\title{
Пространственно-высотные закономерности сроков начала весеннего половодья на водотоках бассейна реки Белая
}

\author{
А.О. Миннегалиев $\bowtie$ \\ Башкирский государственный университет, Российская Федераиия \\ (450076, Республика Башкортостан, г. Уфа, ул. Заки Валиди, 32)
}

\begin{abstract}
Аннотация: Работа выполнена с целью уточнения пространственно-высотных закономерностей сроков начала половодья с учетом последних лет наблюдений на 73 гидрологических постах территории в бассейне реки Белая.

Методы и материальь. Для анализа массивов сроковых характеристик использован алгоритм преобразования дат в числовой формат. Анализ пространственных закономерностей выполнен с использованием инструментария программного комплекса ArcGIS 10.3, выявление высотных закономерностей произведено с использованием метода линейных трендов.

Результаты и обсуждения. В выполненных работах выделен ряд закономерностей и составлена картосхема средних многолетних сроков начала весеннего половодья. Установлено, что пространственные закономерности в пределах территории проявляются в смещении на более позднее время дат начала половодья при движении с юга на север и с запада на восток. Интенсивность смещения достигает для широтной составляющей 9 суток, для секторной - 5. Выделенные широтно-секторные закономерности нарушаются влиянием рельефа, в юго-западной части бассейна в пределах отрогов Общего Сырта и в восточной части бассейна в пределах горных сооружений Урала, где выявлено смещение дат на более поздние сроки, а в центре горной зоны выделена выраженная, глубиной 5-8 суток, положительная аномалия сроков начала половодья.

Заключение. Полученные выводы согласуются с ранее опубликованными по теме исследования материалами и не противоречат общим представлениям о процессе формирования весеннего половодья. Представленная картосхема может быть использована для предварительных расчетов средней многолетней даты начала половодья.
\end{abstract}

Ключевые слова: весеннее половодье, дата начала половодья, картирование гидрологических характеристик, анализ дат наступления, карта даты начала половодья, пространственно-высотные закономерности, бассейн р. Белая.

Для цитирования: Миннегалиев А.О. Пространственно-высотные закономерности сроков начала весеннего половодья на водотоках бассейна реки Белая // Вестник Воронежского государственного университета. Серия География. Геоэкология, 2020, №3, с. 32-39.

DOI: https://doi.org/10.17308/geo.2020.3/3021

\section{ВВЕДЕНИЕ}

Изучение времени наступления основных фаз водного, ледового и термического режима рек является важной задачей гидрологических исследований. При этом наиболее сложной и ответственной задачей является оценка времени наступления периода максимального стока, приуроченного в пределах основной части РФ к весеннему периоду. Оценка сроков наступления характерных дат для половодного периода необходима при строи- тельстве сооружений, сопрягающихся с водотоками, планировании водохозяйственной и природоохранной деятельности.

В связи с этим особенно актуальной становится задача уточнения (с учетом последних лет наблюдений) существующих и выявления новых пространственно-высотных закономерностей в наступлении характерных сроков весеннего половодья и последующего использования полученных закономерностей для расчета обеспеченных харак-

() Миннегалиев А.О., 2020

\ Миннегалиев Александр Олегович, e-mail: minnegaliev.aleksandr@rambler.ru

Контент доступен под лицензией Creative Commons Attribution 4.0 License. 
теристик и составления прогнозов различной заблаговременности. В данной статье представлены результаты выявления описанных закономерностей для бассейна реки Белая.

Наиболее изученными для бассейна характеристиками весеннего половодья являются максимальные расходы и суммарные слои стока. Из работ, относящихся к временным характеристикам, следует упомянуть серию статей [2, 3], в которых рассматриваются вопросы прогноза сроков наступления половодья для отдельных створов бассейна. Кроме того, для территории имеется картосхема средних сроков начала весеннего половодья [6], составленная в границах Среднего Урала и Приуралья по материалам наблюдений до 1967 года. Из относительно недавно опубликованных картографических материалов выделим составленную по материалам наблюдений до 2000 года карту сроков начала половодья бассейна в административных границах республики Башкортостан [1].

Пространственные особенности наступления характерных дат, регрессионные зависимости средней продолжительности половодья от морфометрических факторов рассмотрены ранее в работах $[7,4]$. В представленной статье в продолжение цикла упомянутых исследований рассмотрены закономерности сроков начала весеннего половодья на водотоках бассейна.

Основные положения статьи прошли апробацию по результатам секционного доклада «Некоторые особенности снеготаяния в бассейне реки Белой» на III Межрегиональной научно-практической конференции, посвященной Международному Дню воды (г. Уфа, 23 марта 2018 г.). В представленной статье положения указанного доклада были существенно дополнены за счет увеличения количества исходных пунктов наблюдений и усложнения методики анализа.

\section{МАТЕРИАЛЫ И МЕТОДЫ ИССЛЕДОВАНИЙ}

Объектом исследования является бассейн река Белая - крупный левый приток реки Кама. Бассейн реки имеет площадь 142000 км²$^{2}$, длина реки 1430 км [5]. Речной бассейн располагается в лесной, лесостепной и степной зонах. Располагается примерно в равных по размеру горной (восточной) и равнинной (западной) частей. Водный режим водотоков бассейна характеризуется четко выраженным снеговым весенним половодьем, устойчивой (в равнинной части) или прерывистой (в горной части) летней меженью и устойчивой глубокой зимней меженью.
Предмет исследования - даты начала половодья на водотоках бассейна, основная цель статьи - выявление пространственно-высотных закономерностей в сроках начала половодья. С этой целью для изученных водотоков территории, ограниченной водоразделом реки Белая выполнена систематизация результатов наблюдений за погодичными сроками начала половодья на 73 водотоках (пункты наблюдений схематично нанесены на рисунке 1) за период с первых наблюдений до 2010 года. Средняя длина сформированных массивов составила 41 год, наибольшая - 133 года, наименьшая -8 лет. Суммарный объем исходного массива составил 3028 годопунктов.

Следует отметить, что главной особенностью массивов дат является характерный формат представления, усложняющий сравнение и последующий анализ данных. Методика работы с характерными датами несколько отлична от работы с прочими, преимущественно числовыми, в том числе стоковыми характеристиками.

В связи с этим перед последующим анализом дат применен следующий алгоритм преобразования.

1. В качестве основного формата отображения принято рекомендованное ГОСТ Р6.30-2003 представление в виде «число.месяц.год».

2. С целью возможности последующего сравнения дат за разные годы в качестве параметра год принято единое значение «2016», а для последующей обратной интерпретации в массивы данных введен дополнительный параметр, отображающий фактическое значение года.

3. С целью возможности восстановления рядов данных для массивов дат выполнено преобразование дат в числовой формат, с последующим отсечением значения «42400». Значение отсекаемой части выбрано подбором как максимальное возможное, при котором любое значение в массиве рядов остается положительным. После восстановления рядов выполнено обратное преобразование.

Ряды исходного массива подвергнуты восстановлению с использованием метода множественной линейной регрессии. Суммарный объем после восстановления увеличился до 6008 годопунктов, средняя длина ряда возросла до 82 лет. Для полученных массивов восстановленных характеристик определены значения средних многолетних дат начала весеннего половодья.

Выявление пространственных закономерностей выполнялось на основании построения карт изолиний с использованием Мастера операций геостатистики (Geostratical Wizard) программно- 
го комплекса ArcGIS 10.3. В качестве основного метода картирования принят простой кригинг. Нормирование массивов выполнено с использованием метода «Бокс-кокс» (порядок степени принят равным 4.7), принятый тип модели - «устойчивая». В результате получена растровая модель, по которой наведены изолинии и составлена картосхема (рис. 1).

С целью выявления высотных особенностей применялся графический метод и метод линейных трендов. При анализе влияния рельефа на сроки дополнительно использованы обработанные и совмещенные с итоговой картосхемой материалы радарной топографической съемки (Shuttle Radar Topography Mission) $[8,9]$.

\section{РЕЗУЛЬТАТЫ И ОБСУЖДЕНИЕ}

Полученная картосхема хорошо согласуется с результатами, представленными в работах $[6,1]$. В целом общий характер расположения изохрон и направления изменений соответствуют материалам, приведенным в ранее опубликованных работах, несмотря на то, что между картосхемами имеются различия в показателях пространственного разрешения, шага горизонталей и используемого для осреднения периода наблюдений. При этом выбранное пространственное разрешение (бассейн р. Белая) и шаг горизонталей (1 сутки) позволяют более точно оценить пространственно-высотные особенности сроков начала весеннего половодья.

В результате анализа полученной картосхемы установлено, что пространственное распределение дат начала половодья характеризуется совокупностью выраженных закономерностей, среди которых выделяется ряд пространственно-высотных трендов.

Наиболее явный характер носит широтная составляющая, проявляющаяся в смещении сроков при движении с севера на юг. Ранние средние даты начала половодья наблюдаются на водотоках южной части территории, дата пика смещается на более поздние сроки при движении на север, а широтная разница в сроках в разных частях достигает 9 суток. Так, на реке Мелеуз у города Мелеуз (южная часть водосбора р. Белой) половодье начинается в среднем 31 марта, а на реке Быстрый Танып у города Чернушка (Пермский край) - 8 апреля. Таким образом, в северной части бассейна половодье начинается позже, чем в южной, а запаздывание достигает 8-9 суток.

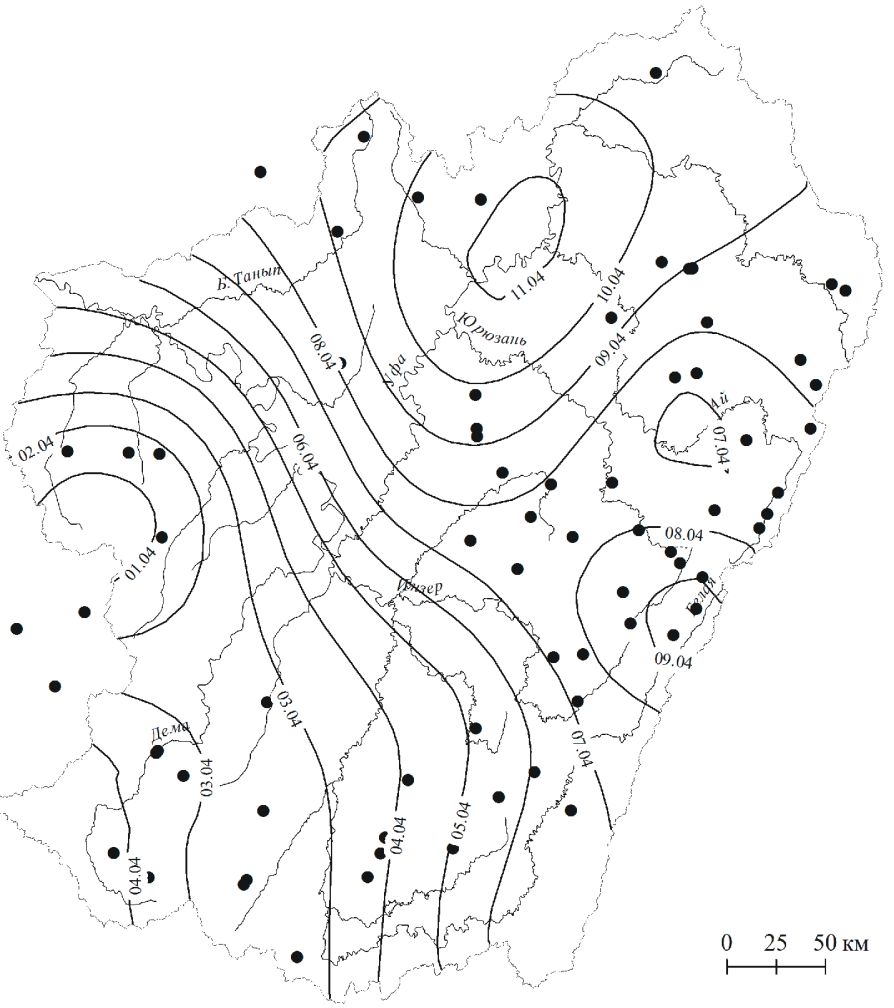

Puc. 1. Средние многолетние даты начала весеннего половодья. Бассейн р. Белая. Точками обозначены пункты стационарной сети наблюдений

[Fig. 1. The mean multi-annual dates of spring flood beginnings. The Belaya River basin. The dots indicate items of the surveillance station network]

Секторное смещение менее выраженное и осложняется влиянием высоты местности. Сравнение средних дат начала по постам, имеющим близкие значения широт центров тяжести и средних высот, показывает, что нарастание сроков происходит в направлении «запад - восток». При этом в пределах равнинной зоны разница достигает 45 суток, а в пределах горной части территории влияние секторной составляющей сложно определить вследствие определяющего влияния характера рельефа. Абсолютные значения параметра нарастания в северной части равнинной зоны достигают 4 суток на 100 км, в южной части - 2 суток на 100 км.

Заметное влияние на дату начала половодья оказывают особенности рельефа. В юго-западной части бассейна, в пределах отрогов Общего Сырта дата начала смещается на более поздние сроки. Величина смещения, определенная по смежным постам с меньшими значениями средней высоты, достигает 3-4 суток, а изохроны заметно отклоняются от широтного простирания.

В свою очередь, в восточной части бассейна, в пределах горной зоны, где рельеф сформирован 
Пространственно-высотные закономерности сроков начала весеннего половодья на водотоках бассейна реки Белая

Оценка влияния рельефа и местоположения на сроки начала половодья

[Table 1. Impact assessment of the relief and location towards the onset of spring floods]

\begin{tabular}{|c|c|c|c|}
\hline Пост / station & $\begin{array}{l}\text { Средняя дата } \\
\text { / mean date }\end{array}$ & $\begin{array}{c}\text { Средняя высота, м / } \\
\text { average altitude, m }\end{array}$ & $\begin{array}{c}\text { Расстояние } \\
\text { м/у постами, } \\
\text { км / distance } \\
\text { between the } \\
\text { stations, km }\end{array}$ \\
\hline \multicolumn{4}{|c|}{ Равнинная зона / Plain area } \\
\hline р. Дема - д. Дюсяново & 04.04 & 262 & \multirow{2}{*}{49} \\
\hline р. Мияки - с. Мияки-Тамак & 01.04 & 272 & \\
\hline р. Мелеуз - г. Мелеуз & 31.03 & 272 & \multirow{2}{*}{395} \\
\hline р. Быстрый Танып - г. Чернушка & 08.04 & 196 & \\
\hline \multicolumn{4}{|c|}{ Горная зона / mountainous area } \\
\hline p. Киги - с. Кондаковка & 04.04 & 357 & \multirow{2}{*}{101} \\
\hline р. Уфа - г. Караидель & 11.04 & 367 & \\
\hline р. Инзер - д. Азово & 05.04 & 600 & \multirow{2}{*}{110} \\
\hline р. Тюлюк - с. Тюлюк & 13.04 & 941 & \\
\hline
\end{tabular}

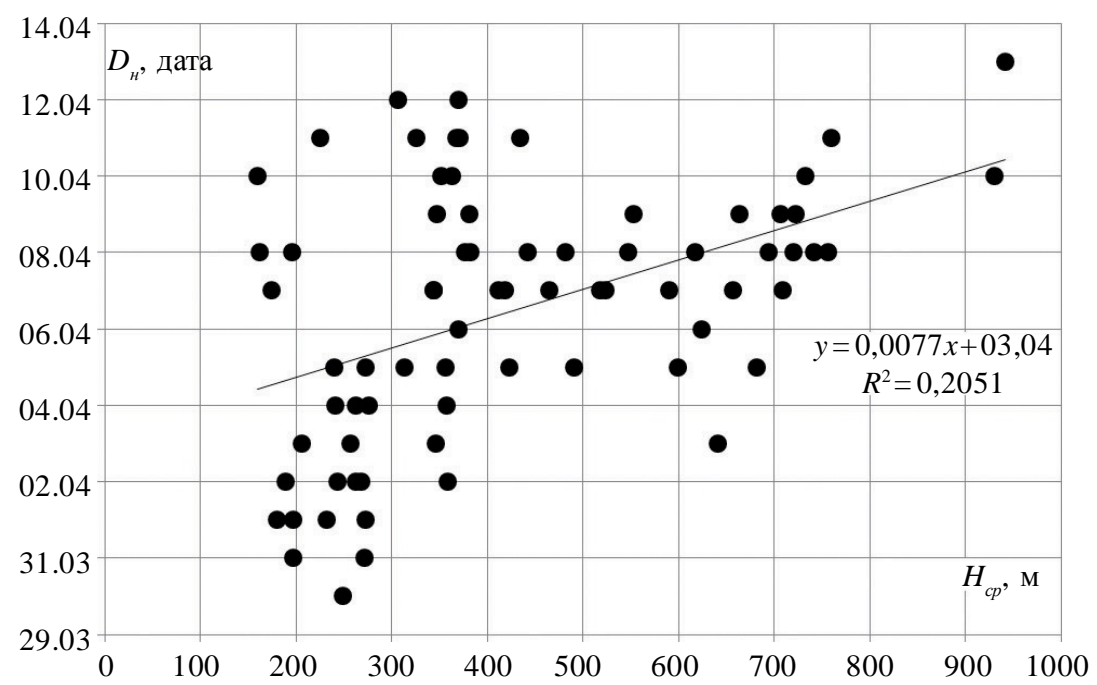

Puc. 2. Зависимость средней многолетней даты начала половодья $\left(D_{t}\right)$ от средней высоты водосбора $\left(H_{c p}\right)$. Бассейн р. Белая

[Fig. 2. The dependence of the mean multi-annual spring flood onset dates $\left(D_{H}\right)$ on the mean elevation of the catchment $\left(H_{c p}\right)$. The Belaya River basin]

складчатыми сооружениями Урала, влияние высоты местности на время начала половодья имеет еще более выраженный характер.

Изолинии дат наступления получают субмеридиональное простирание, а смещение достигает 5 6 суток (таблица 1). Критический анализ результатов влияния средней высоты водосборов на сроки начала половодья позволяет сделать предварительный вывод: для водотоков бассейна р. Белой существует слабо выраженная высотная закономерность, проявляющаяся в виде смещения на более поздние сроки дат начала весеннего поло- водья при увеличении средней высоты водосбора (рис. 2).

При этом последующие попытки выявления функциональной связи между датами начала и средней высотой водосбора не увенчались успехом. Предположительно, описанная связь присутствует и усложняется влиянием экспозиции склонов и барьерностью рельефа.

Влияние высотной составляющей приводит к тому, что в пределах восточной горной части бассейна половодье начинается позже, чем в западной равнинной части, а наложение высотной и 
Количественные характеристики аномалии средних сроков начала половодья

[Table 2. Quantitative characteristics of deviations in the mean values of spring flood onset dates]

\begin{tabular}{|c|c|c|c|c|c|}
\hline \multicolumn{4}{|c|}{$\begin{array}{l}\text { Пост, средние многолетние сроки начала половодья } \\
\text { / Station, mean multi-annual dates of spring flood beginnings }\end{array}$} & \multirow{2}{*}{$\begin{array}{c}\text { Расстоя- } \\
\text { ние, км / } \\
\text { distance, } \\
\text { km }\end{array}$} & \multirow{2}{*}{$\begin{array}{c}\text { Соотно- } \\
\text { шение } \\
\text { высот, м / } \\
\text { correlation } \\
\text { of } \\
\text { elevations, } \\
\text { m }\end{array}$} \\
\hline $\begin{array}{l}\text { в пределах аномального } \\
\text { / within the abnormal }\end{array}$ & частка & $\begin{array}{c}\text { за пределами аномаль } \\
\text { участка } \\
\text { / outside the abnormal }\end{array}$ & & & \\
\hline р. Киги - с. Кондаковка & 04.IV & р. Куса - п. Магнитка & 09.IV & 71.7 & $360 / 550$ \\
\hline p. Ай - с. Лаклы & 07.IV & p. Тесьма - г. Златоуст & 07.IV & 33.0 & $520 / 660$ \\
\hline $\begin{array}{l}\text { p. Ай - п. Орловский } \\
\text { рудник }\end{array}$ & 05.IV & p. Ай - с. Веселовка & 09.IV & 8.1 & $680 / 710$ \\
\hline $\begin{array}{l}\text { p. М. Сатка - п. } \\
\text { Евдокимово }\end{array}$ & 06.IV & p. Ай - с. Веселовка & 09.IV & 24.7 & $690 / 710$ \\
\hline р. Юрюзань - п. Атняш & 07.IV & p. Юрюзань - п. Вязовая & 08.IV & 46.1 & $520 / 690$ \\
\hline
\end{tabular}

пространственной составляющих обуславливает преимущественно субмеридиональное расположение изолиний дат начала.

Следует отметить, что выделенные пространственные и высотные закономерности нарушаются в центральной части горной зоны. В соответствии с картосхемой (рис. 1) здесь, в районе верхнего течения рек Ай и Юрюзань, формируется выраженная положительная аномалия времени начала половодья. Указанная аномалия представляет собой совокупность вытянутых с юго-запада на северо-восток горизонталей, формирующих ложбину, в пределах которой начало половодья в среднем многолетнем разрезе смещается на 5-8 суток к более ранним срокам.

Количественные характеристики описанной аномалии приведены в таблице 2 .

Крупномасштабный фрагмент картосхемы сроков начала половодья для участка верхнего течения рек Ай и Юрюзань приведен на рисунке 3.

Аномалия занимает верхнюю часть бассейнов рек Юрюзань и Уфа, центральная часть ее располагается в треугольнике, образованном постами p. Юрюзань - пос. Атняш - р. Киги - с. Кондаковка - р. Ай - г. Златоуст. Анализ количественных характеристик показывает, что на территории, не превышающей 130 км с запада на восток и 85 км с севера на юг, наблюдается смещение сроков соизмеримое с изменением, наблюдаемым между крайними южной и северной точками равнинной части бассейна, расположенными на расстоянии около 450 км друг от друга. Смещение наблюдается, несмотря на незначительное расстояние и небольшую разницу средних высот водосборов и харак- терно даже для участков крупных рек с небольшим нарастанием притока, что позволяет исключить площадь водосбора как фактор, определяющий это явление.

Границы выявленной аномалии не совпадают с границами природно-климатических зон и не соотносятся напрямую с рельефом местности. Однако предположение об ошибках в исходных данных не подтверждается: перебор с удалением отдельных постов не приводит к существенному изменению направления изолиний и заметному смещению границ аномального участка.

\section{ЗАКЛЮЧЕНИЕ}

Для бассейна реки Белая рассмотрены закономерности в сроках начала весеннего половодья. Установлено, что в пределах бассейна на время начала периода талого стока оказывают влияние пространственно-высотные особенности участка размещения отдельных суббасейнов. Эти особенности в масштабах всего бассейна проявляются в виде широтной составляющей, обуславливающей запаздывание средних многолетних сроков начала при движении с севера на юг, и долготной составляющей, обуславливающей смещение на более поздние сроки при движении с запада на восток. На пространственные тренды накладывается влияние рельефа, проявляющееся в виде смещения сроков начала на более поздние даты при увеличении средней высоты суббассейна. В результате влияния рельефа в пределах территории изохроны приобретают субмеридиональное простирание, а также формируются отрицательные аномалии в юго-западной части территории в пределах Общего Сырта и в восточной части территории в 


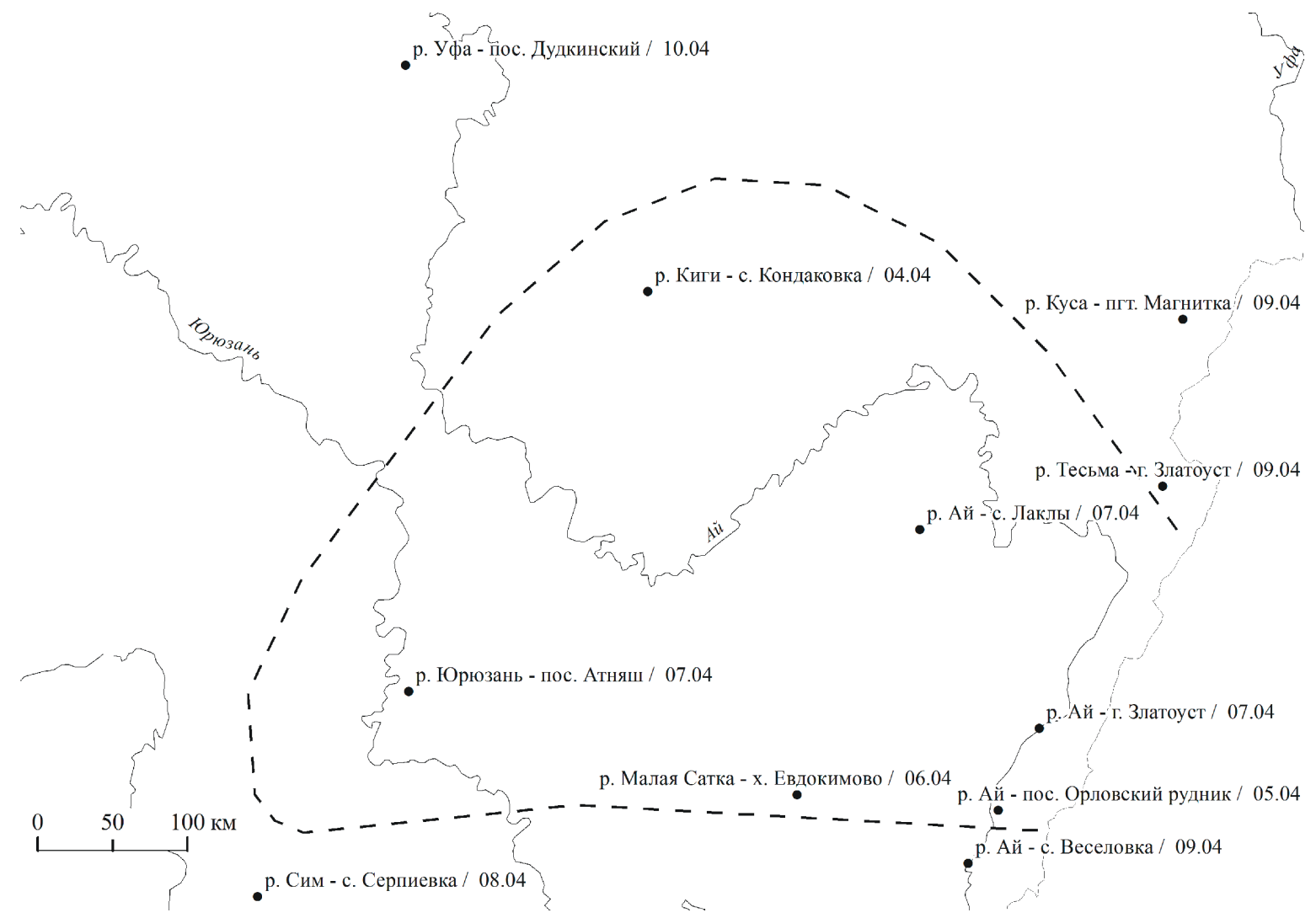

Рuc. 3. Положительная аномалия средних многолетних сроков начала половодья в северо-восточной части бассейна р. Белая. Пунктиром нанесена ориентировочная граница аномалии сроков. Через косую черту для гидрологических постов приведены средние многолетние даты начала весеннего половодья

[Fig. 3. Positive deviation of the mean multi-annual dates of the onset of spring floods in the northeastern area of the

Belaya River basin. The dotted line indicates the approximate borders of the anomaly in the terms. The mean multiannual dates of spring flood onsets for various hydrological surveillance stations are supplied after the slash]

пределах горных сооружений Урала. Кроме того, крупная положительная аномалия сроков начала половодья выявлена в пределах центральной части горной зоны.

В целом полученные результаты согласуются с представлениями о процессе формирования весеннего половодья в пределах исследуемой территории и могут быть использованы в вспомогательных целях при расчете обеспеченных характеристик и создании прогнозных моделей различной заблаговременности.

\section{СПИСОК ЛИТЕРАТУРЫ}

1. Гареев А.М., Гареев Э. А. Сроки начала половодья // Атлас республики Башкортостан / под ред. И. М. Япарова. Уфа: ГУП «ГРИ «Башкортостан»», 2005. $420 \mathrm{c}$.

2. Красногорская Н.Н., Нафикова Э.В., Ферапонтов Ю.И. Оценка и прогнозирование экстремальных гидрологических ситуаций // Современные проблемы науки и образования, 2012, № 1, с. 292.
3. Красногорская Н. Н, Ферапонтов Ю. И., Нафикова Э. В. Разработка методов прогнозирования гидрологических процессов для задач управления водными ресурсами // Ученые записки Российского государственного гидрометеорологического университета, 2013, № 28, c. 43-50.

4. Миннегалиев А. О. Зависимости средней продолжительности половодья от морфометрических характеристик водосборов (на примере бассейна р. Белой) // Вестник Удмуртского университета. Серия Биология. Науки о Земле, 2018, т. 28, № 4, с. 427-433.

5. Ресурсы поверхностных вод СССР: Гидрологическая изученность. Т. 11. Средний Урал и Приуралье. Вып. 1. Кама / под ред. В. В. Николаенко. Л., Гидрометеоиздат, 1966. 324 с.

6. Ресурсы поверхностных вод СССР: Т. 11. Средний Урал и Приуралье / под ред. Н. М. Алюшинской. Л.: Гидрометеоиздат, 1973. 848 с.

7. Стахеева А.А., Миннегалиев А.О. Некоторые особенности наступления характерных дат весеннего половодья на водотоках бассейна реки Белой // Геосфера: сборник научных статей студентов, магистран- 
тов, аспирантов и молодых ученых географического факультета. Уфа: БашГУ, 2017, вып. 10, с. 197-198.

8. Farr T. G., Rosen P.A., Caro E. at al. The shuttle radar topography mission // Reviews of Geophysics, 2007, vol. 45, issue 2, pp. 1-33.

9. Heatwole C., Benharn B. L. Comparison of watershed boundaries derived from SRTM and ASTER digital elevation datasets and from a digitized topographic map // ASABE Annual International Meeting. Minneapolis, Minnesota, 2007, pp. 1-10.

Конфликт интересов: Автор декларирует отсутствие явных и потенци-альных конфликтов интересов, связанных с публикацией настоящей статьи.

Поступила в редакциию 06.12.2019

Принята к публикации: 26.07.2020

UDC 556.5

ISSN 1609-0683

DOI: https://doi.org/10.17308/geo.2020.3/3021

\title{
Spatial and Altitudinal Regular Patterns of the Mean Multiannual Values of Snowmelt Flood Beginning at Watercourses of the Belaya River Basin
}

\author{
A.O. Minnegaliev $\bowtie$ \\ Bashkir State University, Russian Federation \\ (32, Zaki Validi st., Ufa, Republic of Bashkortostan, 450076)
}

\begin{abstract}
The research was conducted in order to clarify the spatial and altitudinal regularities of the spring flood onset dates, taking into account the recent years of observations at 73 hydrological stations in the Belaya River basin.

To analyze arrays of time characteristics, an algorithm for converting dates into the numeric format was applied. The analysis of spatial regularities was carried out using the tools of the software package ArcGIS 10.3, while the altitudinal regular patterns were identified using the method of linear trends.

The work performed has resulted in identifying a number of regular patterns and drawing a schematic map of the mean multi-annual dates of the spring flood beginning. It is revealed that the spatial patterns within the territory manifest themselves via a shift to later dates for the beginning of floods while moving from the south to the north and from the west to the east.

The displacement intensity amounts to 9 days for the latitudinal component, and reaches 5 days for the sectoral component. The identified latitudinal-sectoral regularities are contravened due to the relief impact; in the southwestern part of the basin, within the spurs of ObshchySyrt, while in the eastern part of the basin within the mountain structures of the Urals a shift towards the later dates was detected, and it is revealed that the center of the mountainous zone features a pronounced anomaly in the snowmelt flood beginning dates, 58 days in length.

The results obtained can be used both for determining the mean multiannual dates of snowmelt flood beginning and for establishing predictive models. The results obtained are in line with the materials already published on the research topic and do not contradict the general ideas related to the process of spring flood formation. The presented schematic map can be applied for preliminary calculations of the mean multi-annual dates of the spring flood onset.
\end{abstract}

Key words: spring floods, spring flood onset date, mapping hydrological characteristics, onset date analysis, map of flood onset dates, spatial and altitudinal regularities, the Belaya river basin.

For citation: Minnegaliev A. O. Spatial and altitudinal regular patterns of the mean multiannual values of snowmelt flood beginning at watercourses of the Belaya river basin. Vestnik Voronezskogo gosudarstvennogo universiteta. Geografia geoekologia, 2020, No. 3, pp. 32-39. (In Russ.)

DOI: https://doi.org/10.17308/geo.2020.3/3021

(C) Minnegaliev A.O., 2020

\Aleksandr O. Minnegaliev, e-mail: minnegaliev.aleksandr@rambler.ru

The content is available under Creative Commons Attribution 4.0 License. 


\section{REFERENCES}

1. Gareev A. M., Gareev E. A. Sroki nachala polovod'ya [Spring flood onset terms]. Atlas respubliki Bashkortostan / pod red. I. M. Yaparova. Ufa, GUP "GRI "Bashkortostan"”, 2005. 420 p. (In Russ.)

2. Krasnogorskaya N.N., Nafikova E.V., Ferapontov Yu. I. Otsenka i prognozirovanie ekstremal'nikh gidrologicheskikh situatsiy [Assessing and forecasting extreme hydrological situations]. Sovremennye problem nauki $i$ obrazovaniya, 2012, no. 1, pp. 292. (In Russ.)

3. Krasnogorskaya N.N, Ferapontov Yu.I., Nafikova E. V. Razrabotka metodov prognozirovaniya gidrologicheskikh protsessov dlya zadach upravleniya vodnymi resursami [Development of methods of forecasting hydrological processes for water resources management purposes]. Uchenye zapiski Rossiyskogo gosudarstvennogo gidrometeorologicheskogo universiteta, 2013, no. 28, pp. 4350. (In Russ.)

4. Minnegaliev A.O. Zavisimosti sredney prodolzhitel'nosti polovod'ya ot morfometricheskikh kharakteristik vodosborov (na primere basseyna r. Beloy) [Dependences of the mean flood duration on the morphometric characteristics of catchments (on the example of the Belaya river basin)]. Vestnik Udmurtskogo universiteta. Seriya Biologiya, Nauki o Zemle, 2018, v. 28. no. 4, pp. 427433. (In Russ.)

5. Resursy poverkhnostnykh vod SSSR: Gidrologicheskaya izuchennost' [Surface water resources of the

Миннегалиев Александр Олегович

старший преподаватель кафедры гидрометеорологии и геоэкологии Башкирского государственного университета, г. Уфа, Российская Федерация,

ORCID: https://orcid.org/0000-0001-7145-3419, e-mail: minnegaliev.aleksandr@ rambler.ru
USSR: Hydrological studies]. V. 11. Sredniy Ural i Priural'e. V. 1. Kama / pod red. V. V. Nikolaenko. Leningrad, Publ. Gidrometeoizdat, 1966. 324 p. (In Russ.)

6. Resursy poverkhnostnykh vod SSSR [Surface water resources of the USSR]. V. 11. Sredniy Ural I Priural'ye / pod red. N. M. Alyushinskoy. Leningrad, Publ. Gidrometeoizdat, 1973. 848 p. (In Russ.)

7. Stakheeva A. A., Minnegaliev A. O. Nekotorye osobennosti nastupleniya kharakternykh dat vesennego polovod'ya na vodotokakh basseyna reki Beloy [Some peculiarities of the onset of the characteristic dates of spring floods on the watercourses of the Belaya river basin]. Geosfera: sbornik nauchnyh statey studentov, magistrantov, aspirantov I molodykh uchenykh geograficheskogo fakul'teta, no. 10 / otv. red. A. F. Nigmatullin. Ufa, Publ. BashGU, 2017, pp. 197-198. (In Russ.)

8. Farr T. G., Rosen P. A., Caro E. at al. The shuttle radar topography mission. Reviews of Geophysics, 2007, v. 45 , issue 2 , pp 1-33.

9. Heatwole C., Benharn B.L. Comparison of watershed boundaries derived from SRTM and ASTER digital elevation datasets and from a digitized topographic map. ASABE Annual International Meeting. Minneapolis, Minnesota, 2007, pp. 1-10.

Conflict of interests: The author declares no information of obvious and poten-tial conflicts of interest related to the publication of this article.

Received: 06.12.2019

Accepted: 26.07.2020

Aleksandr O. Minnegaliev

Senior Lecturer of the Department of Hydrometeorology and Geoecology, Bashkir State University, Ufa, Russian Federation, ORCID: https://orcid.org/0000-0001-7145-3419, e-mail: minnegaliev.aleksandr@ rambler.ru 